\title{
Post-mating shift towards longer-chain cuticular hydrocarbons drastically reduces female attractiveness to males in a digger wasp
}

\author{
Carlo Polidori $^{\mathrm{a}, \mathrm{b}, *}$, Irene Giordani ${ }^{\mathrm{c}}$, Mareike Wurdack ${ }^{\mathrm{c}, \mathrm{e}}$, José Tormos ${ }^{\mathrm{d}}$, Josep D. Asís ${ }^{\mathrm{d}}$, \\ Thomas Schmitt ${ }^{\mathrm{c}, \mathrm{e}}$

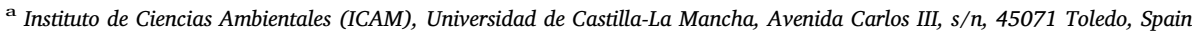 \\ ๖ Centre for Environmental and Marine Studies (CESAM), Departamento de Biologia Animal, Faculdade de Ciências da Universidade de Lisboa, C2-P3 Campo Grande, \\ 1749-016 Lisboa, Portugal \\ ${ }^{c}$ Department of Evolutionary Biology and Animal Ecology, University of Freiburg, Germany \\ ${ }^{\mathrm{a}}$ Unidad de Zoología, Facultad de Biología, Universidad de Salamanca, Spain \\ e Department of Animal Ecology and Tropical Biology, University of Würzburg, Germany
}

\section{A R T I C L E I N F O}

\section{Keywords:}

Chemical cues

Cuticular hydrocarbons

Mating system

Hymenoptera

Stizus

\begin{abstract}
A B S T R A C T
Females of most aculeate Hymenoptera mate only once and males are therefore under a strong competitive pressure which is expected to favour the evolution of rapid detection of virgin females. In several bee species, the cuticular hydrocarbon (CHC) profile exhibited by virgin females elicits male copulation attempts. However, it is still unknown how widespread this type of sexual communication is within Aculeata. Here, we investigated the use of CHCs as mating cues in the digger wasp Stizus continuus, which belongs to the family (Crabronidae) from within bees arose. In field experiments, unmanipulated, recently emerged virgin female dummies promptly elicit male copulation attempts, whereas 1-4 days old mated females dummies were still attractive but to a much lesser extent. In contrast, old (10-15 days) mated female dummies did not attract males at all. After hexanewashing, attractiveness almost disappeared but could be achieved by adding CHC extracts from virgin females even on hexane-washed old mated females. Thus, the chemical base of recognition of females as appropriate mating partner by males is coded in their CHC profile. Accordingly, differences in CHC profiles can be detected between sexes, with males having larger amounts of alkenes and exclusive long-chain alkanes, and within females specially according to their mating status. Shortly after mating, almost all of the major hydrocarbons found on the cuticle of females undergo significant changes in their abundance, with a clear shift from shortchain to long-chain linear and methyl-branched alkanes. The timely detection of virgin females by males in $S$. continuus could be advantageous within the narrow period of female emergence, when male-male competition is strongest.
\end{abstract}

\section{Introduction}

Insects heavily rely on chemical cues and signals for sexual communication (Ayasse et al., 2001; Wyatt, 2014). One sex emits speciesand sex-specific chemical substances or complex bouquets to be recognized by the opposite sex as a potential mating partner. Besides airborne pheromones as long range attractors, cuticular hydrocarbons (CHC) are known to play an important role in chemically-mediated sexual communication in close proximity (Ayasse et al., 2001; Wyatt, 2014; Paxton, 2005; Kroiss et al., 2006; Niehuis et al., 2013). CHCs cover an insect body as a thin layer, and this hydrophobic layer consists of a complex mixtures of mainly long-chain aliphatic alkanes, alkenes and methyl-branched alkanes (Blomquist and Bagneres, 2010). Besides their primary function preventing the bearer from desiccation, abrasion and microbial infestation (Gibbs, 1998), CHCs have also evolved a variety of communicative functions and serve e.g. as sex pheromones, as cues for nestmate recognition, for species and gender recognition as well as dominance and fertility signals (reviewed in Blomquist and Bagneres, 2010). It has been shown that CHC profiles are often species specific and in a number of cases also sex specific (Thomas and Simmons, 2008; Blomquist and Bagneres, 2010). In the case of sex specificity, these CHC profiles are likely to be used by one sex to discriminate between males and females and particularly males use cuticular profiles to adjust proper behavior (Peschke, 1987; Ayasse et al., 2001; Howard and Blomquist, 2005; Peterson et al., 2007).

In several species, the CHC profile changes with an individual's

\footnotetext{
* Corresponding author at: Instituto de Ciencias Ambientales (ICAM), Universidad de Castilla-La Mancha, Avenida Carlos III, s/n, 45071 Toledo, Spain.

E-mail address: carlo.polidori@uclm.es (C. Polidori).
} 
reproductive status and/or age. This change can be either quantitative or in some cases even qualitative. This phenomenon has been studied in some eusocial insects with regard to queen pheromone signaling which is either coupled with fertilization (Keller and Nonacs, 1993; Van Oystaeyen et al., 2014) and/or ovarian development (Le Conte and Hefetz, 2008; Peeters et al., 1999; Bonavita-Cougourdan et al., 1991). Concerning solitary insects, evidence of reproductive status (virgin vs. mated) affecting female CHCs is available for some species from at least four orders (Hymenoptera: Ayasse et al., 2001; Simmons et al., 2003; Diptera: Artis et al., 2012; Kuo et al., 2012; Coleoptera: Peterson et al., 2007; Lepidoptera: Andersson et al., 2000).

Within aculeate Hymenoptera (bees, stinging wasps and ants), alterations of $\mathrm{CHC}$ profiles in females were identified as important source of information about their receptivity (Ayasse et al., 2001; Paxton, 2005; Kroiss et al., 2006). This includes signals (i.e. traits coevolved between sender and receiver for communication) as well as cues (i.e. traits which are provided by senders and used by receivers to acquire information) (Steiger et al., 2011) used by males while searching for an appropriate partner. For example, in bees from at least three families, extracts of CHC profiles from virgin, but not of mated, females, elicit copulatory behavior in males or trigger neuronal responses in male antennae (Ayasse et al., 1999; Paulmier et al., 1999; Schiestl and Ayasse, 2000). This change of CHC profiles can occur as quickly as in $24 \mathrm{~h}$ (the bee Osmia rufa (L.), Dutzler and Ayasse, 1996), three hours (the bee Lasioglossum malachurum (Kirby), Ayasse et al., 1999) or even in $30 \mathrm{~min}$ (the ant Leptothorax gredleri Mayr, Oppelt and Heinze, 2009) after mating. This seems to impose a strong intra-sexual competition onto males, since females are receptive only briefly after emergence (but see Wirtz et al., 1992) and mate only once or few times during their lifetime (Strassmann, 2001; O'Neill, 2001; Paxton et al., 2002).

However, in many lineages of Aculeata, such phenomenon has not been studied yet, limiting knowledge on the evolution of this type of sexual communication. In Apoidea, for example, investigations of this phenomenon were restricted to a few species of bees (Ayasse et al., 1999; Paulmier et al., 1999; Schiestl and Ayasse, 2000; Simmons et al., 2003), but there is a lack of studies on digger wasps, which includes the family (Crabronidae) from within bees arose (Debevec et al., 2012).

In the present study, we investigated whether female attractiveness is mediated by the cuticular chemical profile in the solitary and groundnesting digger wasp Stizus continuus (Klug) (Crabronidae: Bembicinae). Therefore, we analyzed and compared CHC profiles of males and females with different age and mating status, and we conducted behavioral experiments to evaluate how these changes affect female attractiveness to males.

\section{Materials and methods}

\subsection{Study site}

Specimen were collected and experiments performed in the area of "Mallada Llarga" at "Dehesa del Saler", in the "Parque Natural de l'Albufera" (Valencia, Spain: $39.20 \mathrm{~N}-0.40 \mathrm{~W}$ ). Small, thick bushes of Salicornia ramosissima (J. Woods) and Sarcocornia fruticosa (L.), large patches of Juncus maritimus Lam. and Phragmites australis Cav., as well as groves of Pinus maritimus (Morgan) cover most of the study area (Polidori et al., 2008). A large nest aggregation of $S$. continuus (about $200 \mathrm{~m}^{2}$ in total extension, see Polidori et al., 2008) was chosen for the study.

\subsection{Study species}

Stizus continuus is a Mediterranean digger wasp species belonging to the family Crabronidae. At the study site the species is bivoltine, with wasps active from mid of June to end of September (Polidori et al., 2008 , 2010). Each female digs one multicellular nest in an area of bare, sandy soil with sparse vegetation and hunts for orthopterans to feed their offspring (Polidori et al., 2008, 2009; Santoro et al., 2011). Nests are found in aggregations (Asís et al., 1988; Polidori et al., 2008). Males and females emerge from underground nests breaking through the soil surface, creating typical emergence holes. Males emerge earlier than females both in respect of season and daytime (Polidori et al., 2010). Emergence holes are monitored frequently by mate-searching males, some of them eventually establishing territories, of about $200-400 \mathrm{~cm}^{2}$, in areas with a high density of emergence holes (Asís et al., 2006; Polidori et al., 2010). Territorial males are constantly engaged in fights with patrolling males which try to gain territory ownership (Asís et al., 2006). When a (virgin) female emerges, it is immediately harassed by both territorial and patrolling males, with the winner (often the territorial and largest one) promptly copulating with the female (Asís et al., 2006). Once mated, females abandon the nesting site for three to four days, supposedly to feed on flowers, and then return to establish and provision their underground nests (Polidori et al., 2010). At that time, females appear to be no more interested in copulations and their attractiveness to males is strongly reduced or even absent (Asís et al., 2006).

\subsection{Sample collections}

Individuals were collected during their emergence and nesting periods from June to August in the years 2008 to 2015. Virgin females $(n=32)$ and virgin males $(n=10)$ were collected from $8: 00 \mathrm{~h}$ to 13:00 h, i.e. when emergences are known to be most likely to occur (Polidori et al., 2010). We captured virgin individuals by placing empty vials above the typical emergence holes in the ground at the moment of their creation during emergence. Mated females $(n=32)$ and mated males $(n=10)$ (actually males assumed to be mated since they were collected while defending territories or patrolling to search mates) were collected with an entomological net from 10:00 h to 16:00 h, when both female nesting/foraging activity and male patrolling/territorial activity are high (Asís et al., 1988, 2006; Polidori et al., 2009). Since females dig only one nest during their life, any female returning to the nesting area and starting to dig a new nest was considered a young mated female, i.e. 1-4 days after emergence $(n=10)$ (Polidori et al., 2010). These nests were marked with a stick close to the entrance. For a number of these nests, the females were allowed to provision for 10-15 days. These females were collected 11-19 days after emergence and assessed as old mated females $(n=22)$. Upon collection, individuals were freeze-killed and stored at $-20{ }^{\circ} \mathrm{C}$ until chemical extraction and further use.

All collected female individuals were subsequently used as dummies in behavioral assays, and some of the $\mathrm{CHC}$ extracts were also applied to dummies in behavioral tests. The CHC extracts from 10 individuals of each category were analyzed in order to detect differences in their cuticular profiles.

\subsection{Field bioassays}

Behavioral assays using dummies were performed directly at the nesting site, between 10:00 $\mathrm{h}$ and 13:00 h, i.e. the hours of peak male activity. Experiments consisted in recording the behavior of males towards dead de-frosted females (dummies), either intact (i.e. retaining their original cuticular profile), after extracting the whole body in $n$ hexane for $10 \mathrm{~min}$ at room temperature to remove CHCs but not gland contents (e.g. Schmidt et al., 2010; Ruano et al., 2011) or after adding the $\mathrm{CHC}$ extract of two virgin females to hexane-washed old mated females dummies.

For each group (virgin females, young and old mated females, plus washed dummies and old mated females covered with virgin profiles), an experiment consisted of 10-12 trials, each using a different dummy. For each trial, three repetitions with the same dummy were performed at three different spots within the nest aggregation area. Distance between the three spots in each experiment was about 5-10 m, greater 
than the radius of an average male territory (about 1-2 m, see Polidori et al., 2010), thus strongly reducing the probability to test the same males several times. At the end of each trial, the dummy was preserved again in the freezer. The dummy was positioned on the ground in a natural body posture at a randomly chosen spot and was initially kept covered by a vial. Subsequently, the vial was removed and the behavior of males towards the dummy were recorded for two minutes. We recorded 1) the number of male copulation attempts (mounting and hammering with antennae, attempts to copulate) and 2) the number of contacts without any copulation attempts (rapid touches, sometimes with antennation). Mean values across repetitions for each trial were calculated and values per trial were then used in statistical tests to avoid pseudoreplication. Thus, the number of independent replicates for each wasp group was 10-12.

Since normality of distribution of the data were lacking even after transformation (Jarque-Bera test, $J B>10$ (critical value: 5.99)) and variances among groups (i.e. types of tested individuals) were not homogeneous (Levene's test, $F>3$ (critical value: 2.23)) we did not use parametric tests. Instead, we compared medians among types of experiments with the Kruskall-Wallis test (non-parametric analogue to one-way ANOVA). The tests were followed by multiple pairwise comparisons using Dunn's procedure (Dunn, 1964). Linear correlation between behavioral variables was verified with the Pearson test. Statistics of behavioral data were performed with XIStat 2012 (Addinsoft).

\subsection{Chemical analysis}

The CHC profiles of entire individuals were extracted by immersing them in $n$-hexane in glass vials for $10 \mathrm{~min}$. The extracts were stored at $-20{ }^{\circ} \mathrm{C}$ until further analysis. Before the analysis using gas-chromatography coupled with mass spectrometry (GC-MS), the volume of the extracts was reduced to about $200 \mu \mathrm{l}$ using a gentle stream of nitrogen. The GC-MS analysis was performed using a HP 6890 gas chromatograph (GC) coupled with a HP 5973 Mass Selective Detector (MS) (Hewlett Packard, Waldbronn, Germany). The GC (split/splitless-injector in splitless mode for $1 \mathrm{~min}$, injected volume: $1 \mu \mathrm{l}$ at $250{ }^{\circ} \mathrm{C}$ ) was equipped with a DB-5 Fused Silica capillary column $(30 \mathrm{~m} \times 0.25 \mathrm{~mm}$ ID, df $=0.25 \mu \mathrm{m}, \mathrm{J} \& \mathrm{~W}$ Scientific, Folsom, USA). Helium served as a carrier gas at constant flow of $1 \mathrm{ml}$ per minute. The following temperature program was used: start temperature $60{ }^{\circ} \mathrm{C}$, temperature increase by $5{ }^{\circ} \mathrm{C}$ per minute up to $300{ }^{\circ} \mathrm{C}$ and isotherm at $300{ }^{\circ} \mathrm{C}$ for $10 \mathrm{~min}$. The electron ionization mass spectra (EI-MS) were acquired at an ionization voltage of $70 \mathrm{eV}$ (source temperature: $230^{\circ} \mathrm{C}$ ). For recording and the analysis of chromatograms and mass spectra, we used the software HP Enhanced ChemStation G1701AA Version A.03.00.

Once all peaks were quantified, we first eliminated all compounds representing less than $0.1 \%$ of the total abundance across all groups from the dataset. Then, we further eliminated those peaks occurring in less than half of the individuals within each group. The final matrix included 60 peaks (Table 1). Prior to the statistical analysis, we transformed all the variables with the modified Aitchison (1986) method used by Strohm et al. (2008) to avoid undefined values for missing peaks which technically have an area of zero ( $\log 10$ ((relative peak area/geometric mean relative peak area) +1$)$ ).

We tested differences in $\mathrm{CHC}$ profiles among groups with a Discriminant Analysis (DA), preceded by a Principal Component Analysis (PCA). We performed the PCA, in order to reduce the number of variables (peaks), applying a Varimax rotation to the factor axes (dimensions) identified in the initial extraction of factors, in order to obtain simple and interpretable factors (Yaremko et al., 1986). Then, we used the new factor axes to conduct the DA to test whether the groups are separated by discriminant functions. To measure the quality of the DA, Wilk's $\Lambda$ and the correct assignments of individuals to their respective predefined groups were used. All categories of both sexes were entered in both the cluster analysis and the PCA/DA analysis.

Additionally, because we were particularly interested in CHC shift in females after mating and with age, we also compared the abundance of major peaks ( $>1 \%$ abundance in at least one of the compared groups) among virgin, young mated and old mated females with Kruskall-Wallis test followed by multiple pairwise comparisons using Dunn's procedure. Statistics of chemical data were performed with XlStat 2012 (Addinsoft).

\section{Results}

\subsection{Field bioassays}

Female dummies often elicit behavioral reaction from males in our field experiments (Fig. 1A). We found significant differences for each of the two categorized behavioral responses of males among the seven types of dummies (Kruskall-Wallis tests; copulation attempts: $H=47.78, \mathrm{n}=7, p<0.0001$; contacts: $H=47.005, p<0.0001)$ (Fig. 1B).

Males were promptly attracted to dead, intact virgin female dummies, with up to 16 copulation attempts recorded in one single trial (i.e. across three subsequent 2-min tests with the same dummy) (median: 4) (Fig. 1B). Furthermore, $91.6 \%$ of the trials with virgin female dummies were successful in attracting males for copulation attempts. Dead virgin females even attracted sometimes more than one male simultaneously, leading to a typical "mating ball" which closely resembled those observed under natural conditions with live virgin females (Asís et al., 2006). Intact young mated female dummies also attracted males, though to a lesser extent compared with virgin female dummies (median: 1.3 ) (Dunn's procedure: $p=0.07$ ), with up to 7 copulation attempts in a single trial and $80 \%$ of dummies attracting) (Fig. 1B). On the other hand, intact old mated females did not elicit copulatory behavior in males (only one dummy attracted males and the median value of copulation attempts per trial was zero) (Fig. 1B). The attractiveness of virgin female dummies suffered a major reduction when extracted with $n$-hexane before presenting them (median: 0.3 and $67 \%$ of trials with at least one copulation attempt recorded), with the Dunn's procedure showing this reduction significant $(p=0.003)$ (Fig. 1B). All other dummy categories did not elicit copulation attempts after hexanewashing (all medians = 0) (Fig. 1B). However, applying virgin $\mathrm{CHC}$ extracts on washed old mated females activated attractiveness to males, with up to 3 copulation attempts in a single trial, a median value of 0.67 per trial and $40 \%$ of dummies attracting at least once. This acquired attractiveness was similar in strength to that shown by intact young mated females (Dunn's procedure: $p<0.53$ ) (Fig. 1B).

Contacts of males with all types of dummies with no apparent copulatory intentions were relatively common, being $>30$ in some trials and up to 17 for a single trial repetition (Fig. 1C). High numbers of contacts were recorded for both recently emerged females and old mated females (Fig. 1B) and the Dunn's procedure showed that there is no difference between these two groups $(p=0.95)$. All the other groups showed a much lower contact response by males (Fig. 1C).

\subsection{Chemical analysis}

The GC-MS analyses of CHC extracts revealed $n$-alkanes, $n$-alkenes, and mono- and dimethyl-branched alkanes with chain lengths ranging from 23 to 35 carbon atoms on the cuticle of $S$. continuus (Table 1, Fig. S1). From 34 to 45 peaks were detected in each of the groups and the hydrocarbons varied in their proportions (Table 1, Fig. S1).

Males and females presented important differences in CHC compositions, with males tending to exhibit larger proportions of $n$-alkenes than females (Table 1, Fig. S2). Notably only mated males had compounds with chain length $>33$ carbon atoms (Table 1 ).

Females showed also large variation in CHC composition. Virgin females clearly possessed a lower amount of dimethyl-branched alkanes compared with mated females (Fig. S2). Important differences between virgin and mated females appeared also for many individual substances 
Table 1

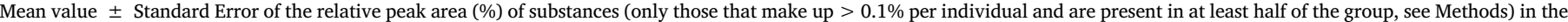

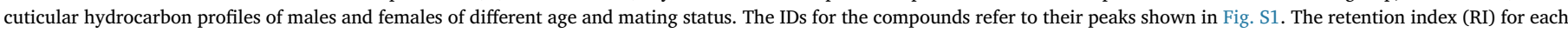

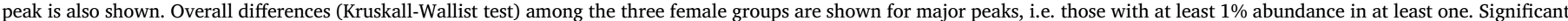

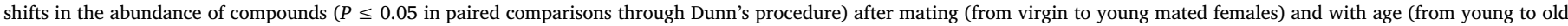
mated females) are highlighted in bold. a and b letters represent different double bond positions in alkenes.

\begin{tabular}{|c|c|c|c|c|c|c|c|}
\hline ID & Substance & Virgin females & Young mated females & Old mated females & Virgin males & Mated males & $\begin{array}{l}\text { Kruskall-Wallis test (among female } \\
\text { groups) }\end{array}$ \\
\hline 1 & $\mathrm{C} 23$ & $3.56 \pm 0.60$ & $0.33 \pm 0.05$ & $0.38 \pm 0.12$ & $0.51 \pm 0.22$ & $0.11 \pm 0.05$ & $\chi^{2}=17.10, P=0.0002$ \\
\hline 2 & 5-MeC23 & $0.09 \pm 0.02$ & 0.00 & 0.00 & 0.00 & 0.00 & \\
\hline 3 & 3-MeC23 & $0.18 \pm 0.03$ & 0.00 & 0.00 & 0.00 & 0.00 & \\
\hline 4 & $\mathrm{C} 24$ & $0.49 \pm 0.06$ & $0.09 \pm 0.03$ & 0.00 & 0.00 & 0.00 & \\
\hline 5 & 3-MeC24/ C25en & $0.26 \pm 0.05$ & 0.00 & $0.69 \pm 0.36$ & 0.00 & 0.00 & \\
\hline 6 & $\mathrm{C} 25$ & $5.90 \pm 0.81$ & $1.39 \pm 0.31$ & $2.17 \pm 0.33$ & $1.71 \pm 0.14$ & $1.83 \pm 0.35$ & $\chi^{2}=15.93, P=0.0003$ \\
\hline 7 & 13- / 11- / 9-MeC25 & $2.87 \pm 0.38$ & $0.40 \pm 0.11$ & $0.98 \pm 0.45$ & $0.56 \pm 0.22$ & $0.65 \pm 0.28$ & $\chi^{2}=16.02, P=0.0003$ \\
\hline 8 & 7-MeC25 & $0.19 \pm 0.02$ & 0.00 & $0.50 \pm 0.18$ & 0.00 & $0.15 \pm 0.04$ & \\
\hline 9 & 5-MeC25 & $0.37 \pm 0.05$ & $0.10 \pm 0.03$ & $0.30 \pm 0.07$ & $0.12 \pm 0.04$ & $0.09 \pm 0.03$ & \\
\hline 10 & 3-MeC25 & $2.17 \pm 0.25$ & $0.65 \pm 0.09$ & $1.71 \pm 0.53$ & $1.27 \pm 0.18$ & $1.08 \pm 0.15$ & $\chi^{2}=13.78, P=0.010$ \\
\hline 11 & $\begin{array}{l}\text { 5,9- / 5,11- / 5,13- / 5,15- } \\
\text { diMeC25 }\end{array}$ & $0.21 \pm 0.04$ & 0.00 & $0.30 \pm 0.09$ & 0.00 & $0.19 \pm 0.07$ & \\
\hline 12 & $\mathrm{C} 26$ & $1.20 \pm 0.05$ & $0.63 \pm 0.06$ & $0.67 \pm 0.07$ & $0.70 \pm 0.05$ & $0.59 \pm 0.03$ & $\chi^{2}=19.56, P=0.0001$ \\
\hline 13 & 3,11-diMeC25 & $0.36 \pm 0.15$ & 0.00 & 0.00 & 0.00 & 0.00 & \\
\hline 14 & 3,7-diMeC25 & 0.00 & 0.00 & $0.40 \pm 0.09$ & $0.10 \pm 0.05$ & $0.18 \pm 0.07$ & \\
\hline 15 & 13- / 12- / 11- / 10- / 9-MeC26 & $1.23 \pm 0.08$ & $0.42 \pm 0.06$ & $0.49 \pm 0.10$ & $0.65 \pm 0.08$ & $0.64 \pm 0.08$ & $\chi^{2}=17.55, \mathrm{P}=0.0002$ \\
\hline 16 & 8,10-diMeC26 & 0.00 & 0.00 & $0.23 \pm 0.07$ & 0.00 & 0.00 & \\
\hline 17 & 4-MeC26 & $0.19 \pm 0.03$ & 0.00 & 0.00 & 0.00 & 0.00 & \\
\hline 18 & $3-\mathrm{MeC} 26 / \mathrm{C} 27 \mathrm{en}^{\mathrm{a}}$ & $2.79 \pm 0.80$ & $1.79 \pm 0.37$ & $3.75 \pm 0.82$ & $5.42 \pm 0.39$ & $4.51 \pm 0.69$ & $\chi^{2}=2.88, P=0.23$ \\
\hline 19 & $\mathrm{C} 27 \mathrm{en}^{\mathrm{b}}$ & 0.00 & 0.00 & $0.33 \pm 0.10$ & $0.28 \pm 0.04$ & 0.00 & \\
\hline 20 & $\mathrm{C} 27$ & $17.23 \pm 0.90$ & $13.13 \pm 1.48$ & $12.76 \pm 1.67$ & $14.64 \pm 1.10$ & $12.68 \pm 1.21$ & $\chi^{2}=5.49, P=0.06$ \\
\hline 21 & 13- / 11- / 9-MeC27 & $22.95 \pm 1.21$ & $11.42 \pm 1.34$ & $9.47 \pm 1.21$ & $20.34 \pm 1.73$ & $18.28 \pm 1.63$ & $\chi^{2}=19.17, \mathrm{P}=0.0001$ \\
\hline 22 & 7-MeC27 & $1.23 \pm 0.09$ & $1.89 \pm 0.19$ & $1.59 \pm 0.25$ & $1.61 \pm 0.14$ & $1.67 \pm 0.12$ & $\chi^{2}=3.93, P=0.14$ \\
\hline 23 & 5-MeC27 & $2.01 \pm 0.24$ & $2.58 \pm 0.39$ & $2.48 \pm 0.36$ & $2.18 \pm 0.20$ & $2.10 \pm 0.23$ & $\chi^{2}=2.07, P=0.35$ \\
\hline 24 & 9,13- / 9,15- / 9,17-diMeC27 & $1.34 \pm 0.83$ & 0.00 & $0.14 \pm 0.05$ & $0.36 \pm 0.10$ & $0.44 \pm 0.04$ & $\chi^{2}=18.62, P=0.0001$ \\
\hline 25 & 3-MeC27 & $10.56 \pm 1.10$ & $11.58 \pm 0.71$ & $9.22 \pm 1.14$ & $11.42 \pm 0.39$ & $9.94 \pm 0.31$ & $\chi^{2}=1.83, P=0.39$ \\
\hline 26 & 5,15-diMeC27 & 0.00 & $2.84 \pm 0.64$ & $3.04 \pm 0.53$ & $2.42 \pm 0.47$ & $2.35 \pm 0.47$ & $\chi^{2}=13.79, P=0.001$ \\
\hline 27 & $\mathrm{C} 28$ & $2.23 \pm 0.21$ & $1.77 \pm 0.13$ & $1.52 \pm 0.24$ & $1.51 \pm 0.11$ & $1.32 \pm 0.11$ & $\chi^{2}=4.68, P=0.09$ \\
\hline 28 & 3,15-diMeC27 & 0.00 & $0.73 \pm 0.22$ & $0.71 \pm 0.21$ & 0.00 & 0.00 & \\
\hline 29 & 3,7-diMeC27 & 0.00 & $1.54 \pm 0.41$ & $0.82 \pm 0.26$ & $0.86 \pm 0.09$ & $0.76 \pm 0.18$ & $\chi^{2}=12.65, P=0.0018$ \\
\hline 30 & 14- / 13- /11- / 9-MeC28 & $1.19 \pm 0.11$ & $1.24 \pm 0.17$ & $0.71 \pm 0.17$ & $1.10 \pm 0.09$ & $1.16 \pm 0.11$ & $\chi^{2}=9.87, \mathrm{P}=0.0072$ \\
\hline 31 & 8,12- / 8,14- / 8,16-diMeC28 & 0.00 & $0.67 \pm 0.20$ & $0.59 \pm 0.18$ & $0.37 \pm 0.08$ & $0.54 \pm 0.12$ & \\
\hline 32 & $6-\mathrm{MeC} 28$ & 0.00 & $0.20 \pm 0.02$ & $0.08 \pm 0.03$ & 0.00 & 0.00 & \\
\hline 33 & 5-MeC28 & 0.00 & $0.17 \pm 0.03$ & $0.09 \pm 0.03$ & 0.00 & 0.00 & \\
\hline 34 & 4-MeC28 & $0.17 \pm 0.02$ & $0.36 \pm 0.04$ & $0.20 \pm 0.05$ & $0.07 \pm 0.02$ & $0.11 \pm 0.02$ & \\
\hline 35 & 3-MeC28 / C29en & $1.70 \pm 0.47$ & $3.42 \pm 0.75$ & $1.98 \pm 0.34$ & $5.36 \pm 0.62$ & $6.03 \pm 0.36$ & $\chi^{2}=4.98, P=0.08$ \\
\hline 36 & C29en & 0.00 & 0.00 & 0.00 & $0.66 \pm 0.23$ & 0.00 & \\
\hline 37 & $\mathrm{C} 29$ & $7.63 \pm 0.69$ & $11.65 \pm 0.86$ & $10.52 \pm 1.46$ & $7.74 \pm 0.79$ & $8.02 \pm 0.62$ & $\chi^{2}=8.83, P=0.012$ \\
\hline 38 & 13- /11- / 9-MeC29 & $4.99 \pm 0.58$ & $10.17 \pm 2.00$ & $6.41 \pm 2.03$ & $9.01 \pm 0.40$ & $9.91 \pm 0.65$ & $\chi^{2}=10.33, P=0.0057$ \\
\hline 39 & 7-MeC29 & $0.26 \pm 0.05$ & $1.38 \pm 0.11$ & $0.74 \pm 0.18$ & $0.67 \pm 0.15$ & $0.78 \pm 0.06$ & $\chi^{2}=17.39, P=0.0002$ \\
\hline 40 & $5-\mathrm{MeC} 29$ & $0.73 \pm 0.08$ & $2.41 \pm 0.38$ & $1.89 \pm 0.32$ & $1.13 \pm 0.19$ & $1.30 \pm 0.17$ & $\chi^{2}=13.06, P=0.0015$ \\
\hline 41 & 9,13-diMeC29 & 0.00 & 0.00 & 0.00 & 0.00 & $0.13 \pm 0.04$ & \\
\hline 42 & 7,11- / 7,15- / 7,17-diMeC29 & $0.13 \pm 0.06$ & $0.94 \pm 0.21$ & $0.46 \pm 0.15$ & $0.34 \pm 0.06$ & $0.52 \pm 0.11$ & \\
\hline 43 & $3-\mathrm{MeC} 29$ & $1.16 \pm 0.12$ & $4.34 \pm 0.91$ & $2.94 \pm 1.13$ & $2.04 \pm 0.23$ & $2.01 \pm 0.31$ & $\chi^{2}=9.06, \mathrm{P}=0.0108$ \\
\hline 44 & 5,13- / 5,15- / 5,17-diMeC29 & 0.00 & $2.78 \pm 0.69$ & $1.57 \pm 0.52$ & $1.01 \pm 0.40$ & $1.65 \pm 0.43$ & $\chi^{2}=11.07, P=0.004$ \\
\hline 45 & $\mathrm{C} 30$ & $0.50 \pm 0.04$ & $1.41 \pm 0.25$ & $0.81 \pm 0.15$ & $0.69 \pm 0.10$ & $1.05 \pm 0.12$ & $\chi^{2}=10.11, P=0.006$ \\
\hline 46 & 3,7-diMeC29 & 0.00 & $0.26 \pm 0.10$ & 0.00 & 0.00 & 0.00 & \\
\hline 47 & 15- / 14- /13-MeC30 & 0.00 & $0.43 \pm 0.10$ & $0.10 \pm 0.03$ & $0.21 \pm 0.05$ & $0.36 \pm 0.07$ & \\
\hline 48 & 8,12- / 8,14- / 8,16-diMeC30 & 0.00 & $0.18 \pm 0.07$ & 0.00 & 0.00 & 0.00 & \\
\hline 49 & C31en & 0.00 & $0.48 \pm 0.11$ & $0.26 \pm 0.13$ & $0.36 \pm 0.03$ & $0.56 \pm 0.10$ & \\
\hline 50 & C31 & $0.80 \pm 0.10$ & $1.49 \pm 0.15$ & $1.55 \pm 0.28$ & $1.16 \pm 0.15$ & $2.08 \pm 0.30$ & $\chi^{2}=8.87, P=0.012$ \\
\hline 51 & 15- / 13- /11- / 9-MeC31 & $1.12 \pm 0.29$ & $1.42 \pm 0.32$ & $1.28 \pm 0.46$ & $0.94 \pm 0.17$ & $1.89 \pm 0.30$ & $\chi^{2}=0.70, P=0.70$ \\
\hline 52 & 7-MeC31 & 0.00 & $0.15 \pm 0.04$ & $0.10 \pm 0.03$ & $0.07 \pm 0.02$ & $0.31 \pm 0.08$ & \\
\hline 53 & 5-MeC31 & 0.00 & $0.25 \pm 0.06$ & $0.22 \pm 0.05$ & 0.00 & $0.27 \pm 0.07$ & \\
\hline 54 & $\begin{array}{l}\text { 7,11- / 7,15- / 7,17- / 7,19- } \\
\text { diMeC31 }\end{array}$ & 0.00 & $0.09 \pm 0.04$ & 0.00 & 0.00 & 0.00 & \\
\hline 55 & 3-MeC31 & 0.00 & $0.52 \pm 0.09$ & $0.29 \pm 0.10$ & $0.39 \pm 0.04$ & $0.91 \pm 0.18$ & \\
\hline 56 & $\mathrm{C} 32$ & 0.00 & $0.11 \pm 0.04$ & 0.00 & 0.00 & $0.22 \pm 0.06$ & \\
\hline 57 & $\begin{array}{l}17-/ 15-/ 13-/ 11-/ 9-/ 7- \\
\text { MeC33 }\end{array}$ & 0.00 & $0.12 \pm 0.04$ & 0.00 & 0.00 & $0.34 \pm 0.09$ & \\
\hline 58 & 3-МeC33 & 0.00 & 0.00 & 0.00 & 0.00 & $0.17 \pm 0.06$ & \\
\hline 59 & 13- /11-MeC35 & 0.00 & 0.00 & 0.00 & 0.00 & $0.07 \pm 0.03$ & \\
\hline 60 & 13,23-diMeC35 & 0.00 & 0.00 & 0.00 & 0.00 & $0.09 \pm 0.03$ & \\
\hline
\end{tabular}

(Table 1). In particular, peaks with carbon chain lengths between 23 and 26 were exclusive or much more abundant in virgin females (Table 1). After mating, the CHC profile becomes more complex (Table 1).
When considering only major peaks (those with at least $1 \%$ abundance in at least one group under comparison), significant differences (P $<0.05$ in Kruskall-Wallist test, see Table 1 ) occurred for 19 peaks. The paired Dunn's comparisons showed important changes for almost 

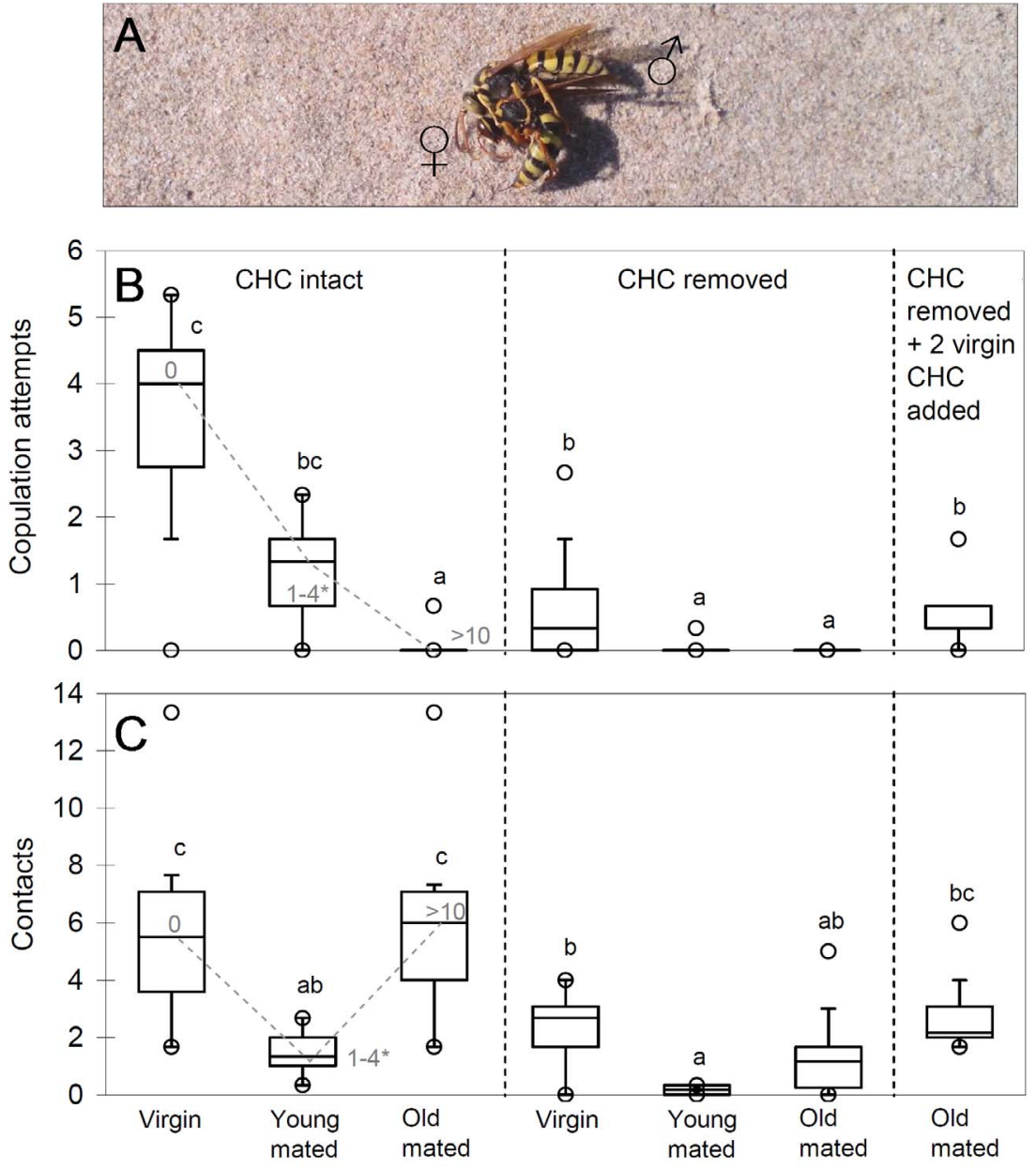

Type of experiment
Fig. 1. A, a copulation attempt by a male $S$. continuus on a virgin female dummy. B-C, box-and-whisker plots showing medians (horizontal lines within boxes), $1^{\circ}$ and $3^{\circ}$ quartile (horizontal lines closing the boxes), and maximum and minimum values $(\mathrm{O})$ for the two types of male behavioral interactions (B: copulation attempts; C, contacts) towards dead intact recently emerged virgin females, dead intact young mated females, dead intact old mated females, dead washed recently emerged virgin females, dead washed young mated females, dead washed old mated females and dead washed young mated females with 2 virgin female profiles added. Ends of the whiskers represent the lowest datum still within $1.5 \times$ interquartile range of the lower quartile, and the highest datum still within $1.5 \times$ interquartile range of the upper quartile. Different letters above the bars were used to show the results of the multiple pairwise comparisons using Dunn's procedure. The boxes of dummies with intact CHC profiles are connected by a dashed grey line in order to evidence trends of behavioral responses in relation to increasing age (expressed as grey numbers; note $\left(^{*}\right)$ that for young mated females the age is expressed as the range including most of cases recorded previously on an independent set of data (see text for details and Polidori et al. (2010)). all of them (18) after mating (from virgin females to young mated females), i.e. for about one third of the total number of peaks detected in females (Table 1, Fig. 2A). Overall, a clear shift towards long-chain CHCs occurred shortly (within four days) after mating (Fig. 2A).

Differences can be detected also, to a smaller extent, between young and old mated females, but significant differences (paired Dunn's comparisons) between young and old mated females were detected only for four major peaks (Table 1, Fig. 2B).

The PCA based on the transformed area of the CHC peaks identified five principal factors accounting on the whole for $73.3 \%$ of the total variance. The greatest contributions $(>5 \%)$ of the principal factor 1 came from six internally mono- or dimethyl-branched alkanes with a carbon chain length between 27 and 29. The principal factor 2 is best determined by internally mono- and dimethyl-branched alkanes, and one linear alkane, with a carbon chain length between 31 and 35. The third factor was mostly correlated with mono- or dimethyl-branched alkanes with a carbon chain length of 25 , the fourth with linear alkanes and monomethyl-branched alkanes with a carbon chain length between 23 and 26, and the fifth factor particularly with 4-monomethyl-C28alkane and 3-monomethyl-C29-alkane.

The subsequent discriminant analysis, based on the five PCA principal factors, calculated five discriminant functions that resulted in a significant separation of all five groups (Wilk's $\Lambda=0.01, \mathrm{~F}=20.3$, $\mathrm{df}=20,137, p<0.0001$; Fig. $3 \mathrm{~A}$ ), with $78 \%$ of individuals correctly assigned to their groups. Discriminant function 1 represented $58.4 \%$ of the variance and mostly separated virgin females from mated females. Discriminant function 2 represented $35.5 \%$ of the variance and separated females from males (Fig. 3A). When the discriminant factor 2 is plotted against the discriminant factor 3 (Fig. 3B), virgin females remained between young mated and old mated females along the discriminant factor 3 (Fig. 3B). The Fisher distances among group centroids were all significantly different (Fisher's distance between 5.3 (mated males vs. virgin males) and 46.2 (virgin females vs. old mated females), all $p<0.001$ ).

\section{Discussion}

There is increasing evidence that females in some taxa of aculeate Hymenoptera loose attractiveness once mated in correspondence with some changes in their $\mathrm{CHC}$ profile. In representatives from five different apoid families (Apidae, Colletidae, Megachilidae, Andrenidae, Halictidae), males were found to be attracted by the CHC profiles of virgin females. Changes in their $\mathrm{CHC}$ profiles after mating were associated with a loss of attractiveness to mate seeking males (Ayasse et al., 1999; Paulmier et al., 1999; Schiestl and Ayasse, 2000; Simmons et al., 2003; Mant and Brändli, 2005). The results of these studies are in accordance with the alteration of CHC profiles in females of the digger wasp $S$. continuus and the loss of attractiveness after mating. Males copulation attempts were drastically reduced towards mated females, although recently mated females elicit more copulation attempts than old mated females. This might be explained by the duration of $\mathrm{CHC}$ changes after mating. The lack of attractiveness of nesting females observed in other digger wasp species (e.g. Tsuneki, 1956; Lomholdt, 1975) suggests that changes in female CHC profiles affecting male behavior could be widespread in this group. Most of ground-nesting bees and wasps are monandrous (Ayasse et al., 2001), so on one hand mated females benefit from decreased harassment by males during nest excavation and provisioning (Smith and Ayasse, 1987; Wcislo, 1987). On 

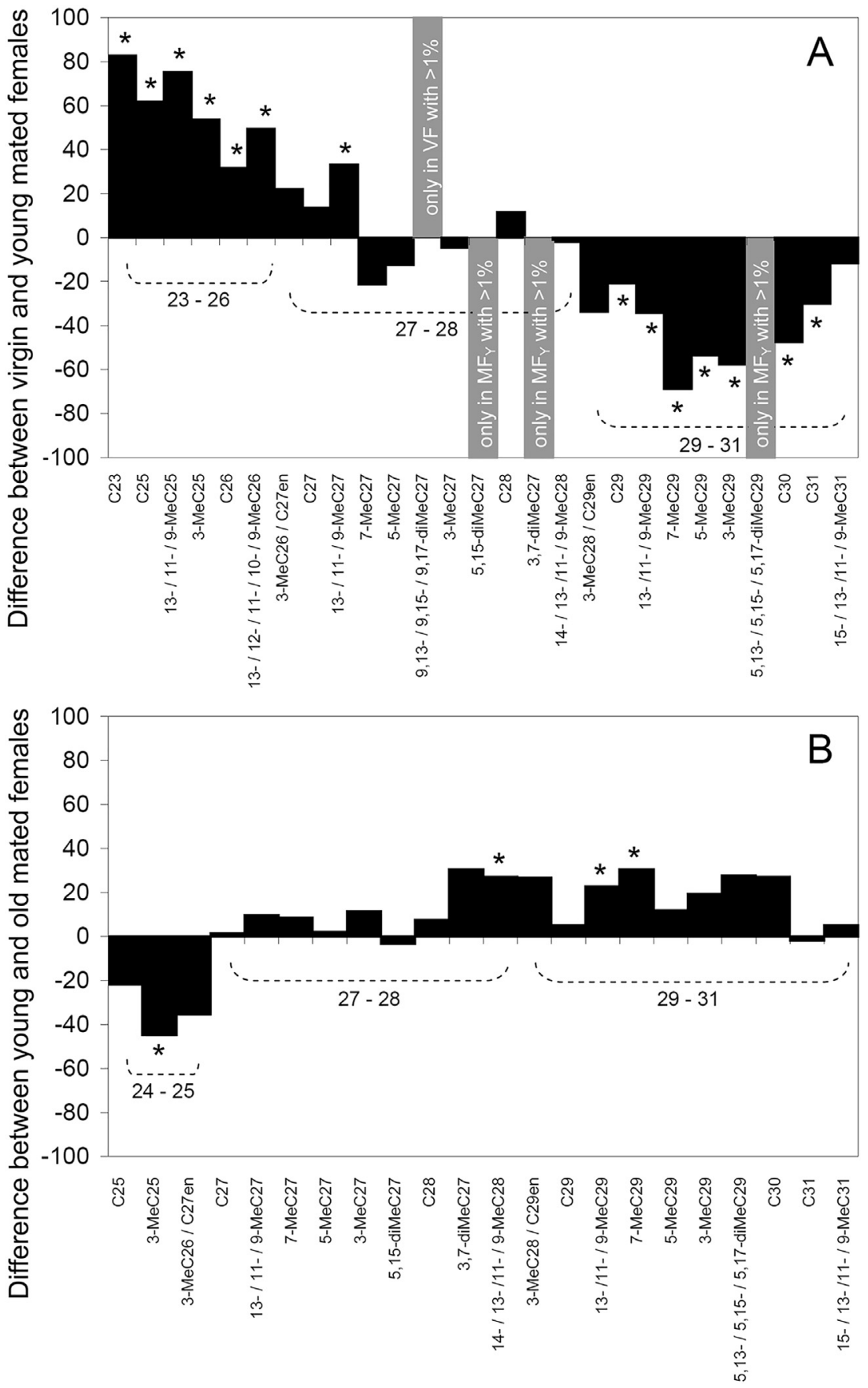

Fig. 2. Standardized differences of the\% abundance of major peaks ( $>1 \%$ in at least one group) between virgin and young mated females (A) and between young mated and old mated females (B) of $S$. continuus ((\% in group $1-\%$ in group 2$) /(\%$ in group $1+\%$ in group $\left.2)^{*} 100\right)$ ). In A, positive bars indicate higher\% in virgin females and negative bars indicate higher\% in young mated females, while in B, positive bars indicate higher\% in young mated females and negative bars indicate higher\% in old mated females. Peaks are ordered by the Retention index (RI). Ranges of carbon chain lengths for the peaks are also shown. The symbol " highlights a significant difference detected by a Dunn's procedure after a Kruskall-Wallist test (see Table 1 for overall statistical differences among the three female groups). the other hand, a rapid discrimination of a proper mating partner is advantageous for males within the narrow time period of female emergence, when male-male competition is highest (Asís et al., 2006).

Male non-copulatory contacts towards the different female categories also varied in frequency. Contacts were frequent towards virgin females (in accordance with their sexual attractiveness), as well as towards old mated females, whereas contacts towards young mated females were less frequent. This variation in contacts is difficult to explain as we were not able to identify specific compounds as pheromones. Potential candidates for eliciting the contacts could be compounds as 3-methyl-branched hydrocarbons which are drastically decreased in young mated females compared to virgin females, but increased again in old mated females (see Table 1). Further experiments are required to fully understand the obtained results on this variation in male behavior.

Females of $S$. continuus usually mate only once in their life. In fact, females generally abandon the emergence/nesting site (where most males occur) after the first copula to avoid harassment by males and return only after 3-4 days to start nesting (Polidori et al., 2010). We found that a shift in the CHC profile of virgin females in their early life as imagos, leads to the loss of their attractiveness. Within the first four days after mating, there is a decrease or even disappearance of certain compounds, particularly alkanes and monomethyl-branched alkanes with shorter chain-length (C23-C26), together with the increase of mostly alkanes with longer chain-length (C28-C33) leading to a reduced attractiveness to males. Thus, males are under a strong competition to find a receptive partner within this short temporal window.

Previous studies on bees as well as on other aculeate hymenopterans showed that changes in female attractiveness via $\mathrm{CHC}$ changes could be either due to an endogenous shift in their cuticular chemistry (Engels and Engels, 1988; Ayasse et al., 1999; Engels et al., 1997; Hora et al., 2008) or because of an anti-aphrodisiac being applied on the female by 

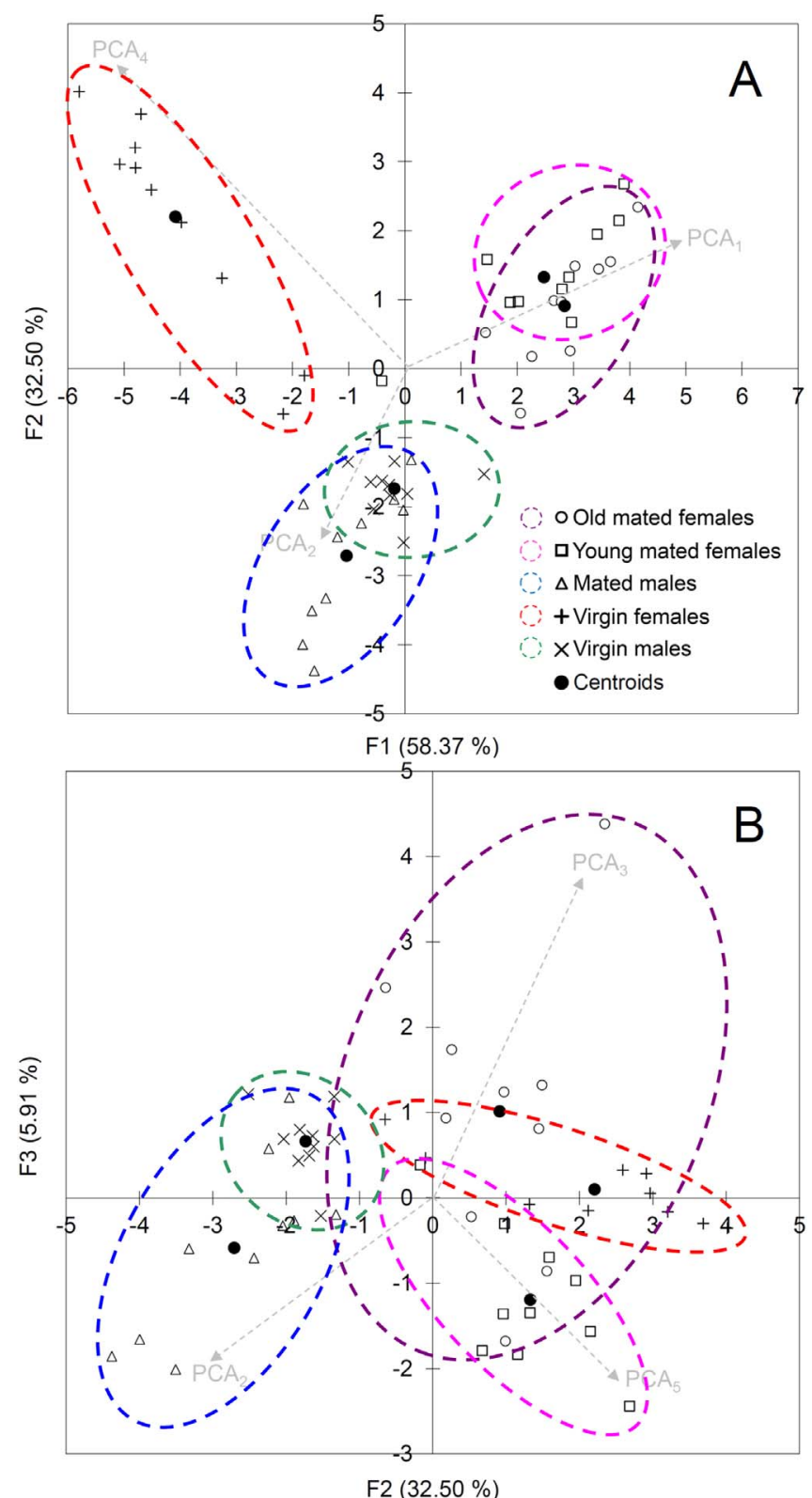

Fig. 3. Discriminant analysis of the cuticular hydrocarbon profiles. A, discriminate function 1 vs. discriminant function 2; B, discriminant function 2 vs. discriminant function 3. Grey arrows and labels indicate the strongest correlations of PCA factors (principal factors extracted by a principal component analysis after varimax rotation) and the discriminant functions.

the copulating male (Kukuk, 1985; Ayasse et al., 2001). Although the discriminant analysis showed a clear separation of male $\mathrm{CHC}$ profiles from the profiles of all female types in $S$. continuus, males do not exhibit exclusive compounds that could serve as anti-aphrodisiac except few long-chain hydrocarbons in mated males. Furthermore, none of these exclusive male CHC compounds were detected exclusively on mated females. We therefore discarded the hypothesis that male CHCs are transferred to females during mating and act as anti-aphrodisiac. It has been suggested that $\mathrm{CHC}$ dimorphism in insects may have evolved due to sexual selection (Thomas and Simmons, 2008), and it is widespread in aculeate Hymenoptera (e.g. Layton et al., 1994; Cuvillier-Hot et al., 2001). It is also unlikely that males transfer gland contents as antiaphrodisiac to females as we did not find any additional exclusive polar or non-polar compound in male gland extracts (dichloromethane extraction of entire specimens for $2 \mathrm{~h}$; data not shown).

Short-chain alkanes and mono methyl-branched alkanes (C23 to

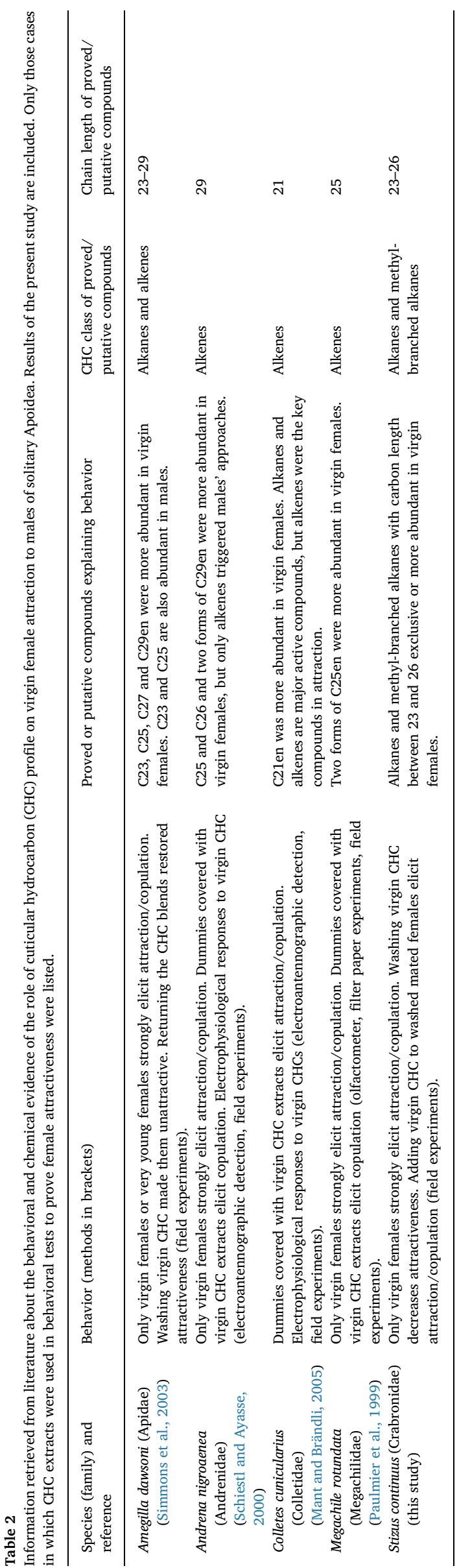


C26) were found in higher proportion in virgin than in mated females of $S$. continuus, suggesting that the cue or signal for their receptivity may be within this chain length range. After mating, a shift towards longerchain alkanes and mono methyl-branched alkanes occurred. A similar shift after mating towards longer-chain alkanes was observed in a solitary anthophorine bee (Simmons et al., 2003). However, literature survey did not support the hypothesis that only short-chain alkanes and methyl-branched alkanes are generally responsible for virgin female attractiveness in Apoidea (Table 2). In a megachilid bee, an andrenid bee, a colletid bee and a bumblebee, either short- or long-chain alkenes are much more abundant in virgin than in mated females (Paulmier et al., 1999; Schiestl and Ayasse, 2000; Simmons et al., 2003; Mant and Brändli, 2005; Jansen et al., 2015) suggesting that alkene-rich profile are responsible in eliciting male copulation in these species (Table 2). However, alkenes were unlikely to play an important role in $S$. continuus female attractiveness, since they are not very abundant on the female cuticle.

Despite the recorded CHC shift after mating, young mated females are still, though very poorly, attractive to males. Rare copulatory attempts towards young mated females was also recorded for another wasp species in the subfamily Bembicinae, Bembix rostrata (Fabr.) (Schöne and Tengö, 1981) and in the bee Amegilla dawsoni Rayment (Simmons et al., 2003). In S. continuus the disappearance of the female attractiveness seems to be related with a further, though smaller, CHC shift from young to old mated females. Age-dependent changes in $\mathrm{CHC}$ profiles are not surprising per se since they normally occur due to physiological ageing processes (metabolism and gland development) and ovarian development (Jansen et al., 2015). For future studies, it would be interesting to examine if the CHC profile of $S$. continuus virgin females also shift with age independently of mating, as it was observed in few bees (Megachile rotundata Fabricius, Paulmier et al. (1999); Lasioglossum zephyrum (Smith), Barrows (1975); Apis mellifera L., Babis et al. (2014)) and few ants (Linepithema humile Mayr, de Biseau et al. (2004); Ectatomma tuberculatum (Olivier), Hora et al. (2008)).

\section{Acknowledgments}

Thanks are due to the Town Hall of Valencia and the Generalitat Valenciana for issuing the permits necessary to carry out part of this work in La Mallada Larga (El Saler). We are indebted to Mareen Geyer and Franziska Bandorf for helping in field data collection. Experiments comply with the current Spanish law. This work was supported by the Junta de Castilla y León [grant number SA094A09]; the Ministerio de Economia y Competitividad (Spanish Government) [grant number CGL2010-16730]; the Deutsche Forschungsgemeinschaft (DFG) [grant number SCHM2645 1-1]; the Fundação para a Ciência e a Tecnologia (FCT) [grant number SFRH/BPD/100460/2014]; a post-doctoral contract to CP by Universidad de Castilla la Mancha and the European Social Fund (ESF); and an exchange fellowship to IG by DAAD.

\section{Appendix A. Supplementary data}

Supplementary data associated with this article can be found, in the online version, at http://dx.doi.org/10.1016/j.jinsphys.2017.05.001.

\section{References}

Andersson, J., Borg-Karlson, A.K., Wiklund, C., 2000. Sexual cooperation and conflict in butterflies: A male-transferred anti-aphrodisiac reduces harassment of recently mated females. Proc. R. Soc. B Biol. Sci. 267, 1271-1275.

Artis, M., Huestes, D., Lehmann, T., 2012. Variation in cuticular hydrocarbons with age, feeding, and insemination status of Anopheles gambiae. FASEB J. 26 (1072), 2.

Asís, J.D., Tormos, J., Jiménez, R., 1988. Contribution to the study of the biology of Stizus continuus (Klug, 1835) (Hymenoptera, Sphecoidea). Entomol. News 99 (199), 208.

Asís, J.D., Tormos, J., Gayubo, S.F., 2006. Territorial dynamics and contest behaviour in the solitary wasp Stizus continuus (Hymenoptera: Apoidea: Crabronidae). Behaviour $143,83-114$.

Aitchison, J., 1986. The Statistical Analysis of Compositional Data. Monographs in statistics and applied probability. Chapman and Hall, London.

Ayasse, M., Engels, W., Lübke, G., Francke, W., 1999. Mating expenditures reduced via female sex pheromone modulation in the primitively eusocial halictine bee, Lasioglossum (Evylaeus) malachurum (Hymenoptera: Halictidae). Behav. Ecol. Sociobiol. 45, 95-106.

Ayasse, M., Paxton, R.J., Tengö, J., 2001. Mating behavior and chemical communication in the order Hymenoptera. Annu. Rev. Entomol. 46, 31-78.

Babis, M., Holman, L., Fenske, R., Thomas, M.L., Baer, B., 2014. Cuticular lipids correlate with age and insemination status in queen honeybees. Insectes Soc. 61, 337-345.

de Biseau, J.-C., Passera, L., Daloze, D., Aron, S., 2004. Ovarian activity correlates with extreme changes in cuticular hydrocarbon profile in the highly polygynous ant, Linepithema humile. J. Insect Physiol. 50, 585-593.

Barrows, E.M., 1975. Mating behavior in halictine bees (Hymenoptera: Halictidae): III. Copulatory behavior and olfactory communication. Insectes Soc. 22, 307-322.

Bonavita-Cougourdan, A., Theraulaz, G., Bagneres, A.-G., Roux, M., Pratte, M., Provost, E., Clement, J.L., 1991. Cuticular hydrocarbons, social organization and ovarian development in a polistine wasp: Polistes dominulus Christ. Comp. Biochem. Physiol. B: Biochem. Mol. Biol. 100, 667-680.

Blomquist, G., Bagneres, A., 2010. Introduction, history and overview of insect hydrocarbons. In: Blomquist, G., Bagneres, A. (Eds.), Insect Hydrocarbons: Biology, Biochemistry and Chemical Ecology. Cambridge University Press, Cambridge, pp. 3-18.

Cuvillier-Hot, V., Cobb, M., Malosse, C., Peeters, C., 2001. Sex, age and ovarian activity affect cuticular hydrocarbons in Diacamma ceylonense, a queenless ant. J. Insect Physiol. 47, 485-493.

Debevec, A.H., Cardinal, S., Danforth, B.N., 2012. Identifying the sister group to the bees: a molecular phylogeny of aculeata with an emphasis on the superfamily Apoidea. Zool. Scr. 41, 527-535.

Dunn, O.J., 1964. Multiple comparisons using rank sums. Technometrics 6 241-241.

Dutzler, G., Ayasse, M., 1996. The function of female sex pheromones in mate selection of Osmia rufa (Megachilidae) bees. In: Proceedings of the XX International Congress of
Entomology. Museo Regionale di Scienze Naturali, Torino, p. 376.

Engels, E., Engels, W., 1988. Age-dependent queen attractiveness for drones and mating in the stingless bee Scaptotrigona postica. J. Apic. Res. 27, 3-8.

Engels, W., Engels, E., Francke, W., 1997. Ontogeny of cephalic volatile patterns in queens and mating biology of the neotropical stingless bee, Scatotrigona postica. Invertebrate Reprod. Dev. 30, 251-256.

Gibbs, A., 1998. Water-proofing properties of cuticular lipids. Am. Zool. 38, 471-482.

Hora, R.R., Ionescu-Hirsh, A., Simon, T., Delabie, J., Robert, J., Fresneau, D., Hefetz, A. 2008. Postmating changes in cuticular chemistry and visual appearance in Ectatomma tuberculatum queens (Formicinae: Ectatomminae). Naturwissenschaften 95, 55-60.

Howard, R.W., Blomquist, G.J., 2005. Ecological, behavioral, and biochemical aspects of insect hydrocarbons. Annu. Rev. Entomol. 13, 371-393.

Jansen, J., Pokorny, T., Schmitt, T., 2015. Disentangling the effect of insemination and ovary development on the cuticular hydrocarbon profile in the bumblebee Bombus terrestris (Hymenoptera: Apidae). Apidologie 47, 101-113.

Keller, L., Nonacs, P., 1993. The role of queen pheromones in social insects: queen control or queen signal? Anim. Behav. 45, 787-794.

Kroiss, J., Schmitt, T., Schreier, P., Strohm, E., Herzner, G., 2006. A selfish unction of a "social" gland? A postpharyngeal gland functions as sex pheromone reservoir in males of a solitary wasp. J. Chem. Ecol. 32, 2763-2776.

Kukuk, P.F., 1985. Evidence for an antiaphrodisiac in the sweat bee Lasioglossum (Dialictus) zephyrum. Science 277, 656-657.

Kuo, T.-H., Yew, J.Y., Fedina, T.Y., Dreisewerd, K., Dierick, H.A., Pletcher, S.D., 2012 Aging modulates cuticular hydrocarbons and sexual attractiveness in Drosophila melanogaster. J. Exp. Biol. 215, 814-821.

Layton, J.M., Camann, M.A., Espelie, K.E., 1994. Cuticular lipid profiles of queens, workers, and males of social wasp Polistes metricus Say are colony-specific. J. Chem. Ecol. 20, 2307-2321.

Le Conte, Y., Hefetz, A., 2008. Primer pheromones in social Hymenoptera. Annu. Rev. Entomol. 53, 523-542.

Lomholdt, O., 1975. The Sphecidae (Hymenoptera) of Fennoscandia and Denmark. Fauna Entomologica Scandinavica 4. Scandinavian Science Press Ltd, Klampen-borg.

Mant, J., Brändli, C., Vereecken, N.J., Schultz, C.M., Francke, W., Schiestl, F.P., 2005. Cuticular hydrocarbons as sex pheromone of the bee Colletes cunicularis and the key to its mimicry by the sexually deceptive orchid, Ophrys exaltata. J. Chem. Ecol. 31, 1765-1787.

Niehuis, O., Buellesbach, J., Gibson, J.D., Pothmann, D., Hanner, C., Mutti, N.S., Judson, A.K., Gadau, J., Ruther, J., Schmitt, T., 2013. Behavioural and genetic analyses of Nasonia shed light on the evolution of sex pheromones. Nature 494, 345-348.

O’Neill, K.M., 2001. Solitary Wasps: Natural History and Behavior. Cornell University Press, Ithaca.

Oppelt, A., Heinze, J., 2009. Mating is associated with immediate changes of the hydrocarbon profile of Leptothorax gredleri ant queens. J. Insect Physiol. 55, 624-628.

Paulmier, I., Bagneres, A.G., Afonso, C.M.M., Dusticier, G., Riviere, G., Clement, J.L., 1999. Alkenes as a sexual pheromone in the alfalfa leaf-cutter bee Megachile 
rotundata. J. Chem. Ecol. 25, 471-490.

Paxton, R.J., Ayasse, M., Field, J., Soro, A., 2002. Complex sociogenetic organization and reproductive skew in a primitively eusocial sweat bee, Lasioglossum malachurum, as revealed by microsatellites. Mol. Ecol. 11, 2405-2416.

Paxton, R.J., 2005. Male mating behaviour and mating systems of bees: an overview. Apidologie 36, 145-156.

Peeters, C., Monnin, T., Malosse, C., 1999. Cuticular hydrocarbons correlated with reproductive status in a queenless ant. Proc. R. Soc. B: Biol. Sci. 266, 1323-1327.

Peterson, M.A., Dobler, S., Larson, E.L., Juarez, D., Schlarbaum, T., Monsen, K.J., Francke, W., 2007. Profiles of cuticular hydrocarbons mediate male mate choice and sexual isolation between hybridising Chrysochus (Coleoptera: Chrysomelidae). Chemoecology 13, 87-96.

Peschke, K., 1987. Male aggression, female mimicry and female choice of the rove beetle, Aleochara curtula (Coleoptera, Staphylinidae). Ethology 75, 65-284.

Polidori, C., Mendiola, P., Asís, J.D., Tormos, J., Selfa, J., Andrietti, F., 2008. Femalefemale attraction influences nest establishment in the digger wasp Stizus continuus (Hymenoptera: Crabronidae). Anim. Behav. 75, 1651-1661.

Polidori, C., Mendiola, P., Asís, J.D., Tormos, J., Garcia, M.D., Selfa, J., 2009. Predatory habits of the grasshopper-hunting wasp Stizus continuus (Hymenoptera: Crabronidae): diet preference, predator-prey size relationships and foraging capacity. J. Nat. Hist. 43, 2985-3000.

Polidori, C., Giordani, I., Mendiola, P., Asís, J.D., Tormos, J., Selfa, J., 2010. Emergence and dispersal relative to natal nest in the digger wasp Stizus continuus (Hymenoptera: Crabronidae). C. R. Biol. 333, 255-264.

Ruano, F., Devers, S., Sanllorente, O., Errard, C., Tinaut, A., Lenoir, A., 2011. A geographical mosaic of coevolution in a slave-making host-parasite system. J. Evol. Biol. 24, 1071-1079.

Santoro, D., Polidori, C., Asís, J.D., Tormos, J., 2011. Complex interactions between components of individual prey specialization affect mechanisms of niche variation in a grasshopper-hunting wasp. J. Anim. Ecol. 80, 1123-1133.

Schiestl, F.P., Ayasse, M., 2000. Post mating odor in females of the solitary bee, Andrena nigroaenea (Apoidea, Andrenidae), inhibits male mating behavior. Behav. Ecol. Sociobiol. 48, 303-307.

Schmidt, A.M., d'Ettorre, P., Pedersen, J.S., 2010. Low levels of nestmate discrimination despite high genetic differentiation in the invasive pharaoh ant. Front. Zool. 7, 20.

Schöne, H., Tengö, J., 1981. Competition of males, courtship behaviour and chemical communication in the digger wasp Bembix rostrata (Hymenoptera, Sphecidae). Behaviour 77, 44-66.

Simmons, L.W., Alcock, J., Reeder, A., 2003. The role of cuticular hydrocarbons in male attraction and repulsion by female Dawson's burrowing bee, Amegilla dawsoni. Anim. Behav. 66, 677-685.

Smith, B.H., Ayasse, M., 1987. Kin-based male mating preferences in two species of halictine bees. Behav. Ecol. Sociobiol. 20, 313-318.

Steiger, S., Schmitt, T., Schaefer, H.M., 2011. The origin and dynamic evolution of chemical information transfer. Proc. R. Soc. B: Biol. Sci. 278, 970-979.

Strassmann, J., 2001. The rarity of multiple mating by females in the social Hymenoptera. Insectes Soc. 48, 1-13.

Strohm, E., Kroiss, J., Herzner, G., Laurien-Kehnen, C., Boland, W., Schreier, P., Schmitt, T., 2008. A cuckoo in wolves' clothing? Chemical mimicry in a specialized cuckoo wasp of the European beewolf (Hymenoptera, Chrysididae and Crabronidae). Front. Zool. 5, 2.

Thomas, M.L., Simmons, L.W., 2008. Sexual dimorphism in cuticular hydrocarbons of the Australian field cricket Teleogryllus oceanicus (Orthoptera: Gryllidae). J. Insect Physiol. 54, 1081-1089.

Tsuneki, K., 1956. Ethological studies on Bembix niponica Smith, with emphasis on the psychobiological analysis of behaviour inside the nest (Hymenoptera, Sphecidae). I. Biological part. Memoirs of the Faculty of Liberal Arts, Fukui University, ser. 2. 6, pp. 77-172.

Van Oystaeyen, A., Oliveira, R.C., Holman, L., van Zweden, J.S., Romero, C., Oi, C.A. d'Ettorre, P., Khalesi, M., Billen, J., Wäckers, F., Millar, J.G., Wenseleers, T., 2014. Conserved class of queen pheromones stops social insect workers from reproducing. Science 343, 287-290.

Yaremko, R.M., Harari, H., Harrison, R.C., Lynn, E., 1986. Handbook of Research and Quantitative Methods in Psychology: For Students and Professionals. Lawrence Erlbaum Associates, Hillsdale.

Wcislo, W.T., 1987. The role of learning in the mating biology of a sweat bee Lasioglossum zephyrum (Hymenoptera: Halictidae). Behav. Ecol. Sociobiol. 20, 179-185.

Wirtz, P., Kopka, S., Schmoll, G., 1992. Phenology of two territorial solitary bees, Anthidium manicatum and A. florientinum (Hymenoptera: Megachilidae). J. Zool. 228, 641-651.

Wyatt, T.D., 2014. Pheromones and Animal Behaviour: Chemical Signals And Signatures. Cambridge University Press, Cambridge. 